\title{
A saúde e o trabalho de médicos de UTI neonatal: um estudo em hospital público no Rio de Janeiro
}

\author{
I ${ }^{1}$ Ana Paula Ferreira Rocha, ${ }^{2}$ Katia Reis de Souza, ${ }^{3}$ Liliane Reis Teixeira |
}

Resumo: Este artigo tem como objetivo conhecer a perspectiva de médicos sobre a saúde e o trabalho em uma unidade de terapia intensiva neonatal de um hospital público do estado do Rio de Janeiro. Para tal, realizou-se pesquisa de cunho qualitativo e de caráter exploratório. Foram realizadas 13 entrevistas individuais e semiestruturadas, com roteiro de perguntas abertas. No que tange à análise dos materiais, adotou-sea técnica de análise do discurso, sendo identificados quatro eixos empíricos de discussão, a saber: elementos da atual configuração do trabalho médico; o trabalho na UTI neonatal; a saúde dos médicos e a prática de automedicação e a necessidade de espaços de diálogo; gênero no trabalho médico e na pediatria. Ao fim, verificou-se que as transformações técnicas e organizacionais do trabalho médico vêm se acelerando e gerando significativas consequências para a vida e a saúde desses trabalhadores. Constatou-se, ainda, preponderância da ausência de vínculos trabalhistas estáveis e precedência de escolha pela atividade de plantôes devido às atuais condições salariais, gerandomaior carga de trabalho. Conclui-sepela necessidade de uma política de valorização profissional abrangente que inclua mudanças na organização laboral a partir dos locais de trabalho com a participação dos trabalhadores.

> Palavras-chave: saúde do trabalhador; medicina e trabalho; organização do trabalho; UTI neonatal; saúde de médicos.

\author{
${ }^{1}$ Centro de Estudos da Saúde \\ do Trabalhador e Ecologia \\ Humana, Fundação Oswaldo \\ Cruz. Rio de Janeiro-RJ, \\ Brasil. Endereço eletrônico: \\ alaneanapaula@uol.com.br \\ ${ }^{2}$ Centro de Estudos da Saúde \\ do Trabalhador e Ecologia \\ Humana, Fundação Oswaldo \\ Cruz. Rio de Janeiro-RJ, Brasil. \\ Endereço eletrônico: katreis@ \\ ensp.fiocruz.br \\ ${ }^{3}$ Centro de Estudos da Saúde do \\ Trabalhador e Ecologia Humana, \\ Fundação Oswaldo Cruz. Rio \\ de Janeiro-RJ, Brasil. Endereço \\ eletrônico: lilianeteixeira@ensp. \\ fiocruz.com.br
}

Recebido em: 10/09/2014 Aprovado em: 09/03/2015 


\section{Introdução}

Nas últimas décadas, a globalização da economia, as grandes mudanças sociais, econômicas e políticas têm levado a uma reconfiguração do mundo do trabalho, afetando diretamente a vida e a saúde dos trabalhadores (GOMEZ; MACHADO; PENA, 2011). Na medicina, têm sido observadas alterações nos saberes e práticas dos médicos, no poder de decisão, na relação médicopaciente, no prestígio e no status a eles sempre dispensados. Associadas a tais mudanças, queixas relacionadas à necessidade de multiemprego (devido à baixa remuneração) e más condições de trabalho foram associadas, diretamente, ao desgaste profissional e sofrimento, levando a repercussōes diferenciadas sobre a saúde desses profissionais (MACHADO, 1997; HENNINGTON, 2011).

Decerto, o labor médico não ficou alheio à nova configuração do mundo do trabalho - notadamente no que se referea desregulamentação e flexibilização dos direitos trabalhistas - apresentando reflexos evidentes na subjetividade desses trabalhadores (BAASH; LANNER, 2011; HENNINGTON, 2011). Para Camargo (2003), é essencial que seja analisado o contexto no quala prática médica se realiza, como as condiçôes concretas de trabalho e as relações de assalariamento. De acordo com o autor, a política de remuneração do trabalho médico (direta ou indiretamente, por salários ou repasses) aponta uma limitação do seu poder e "maximização da mais-valia" do seu trabalho, seguido da proletarização de expressivos segmentos dessa categoria (CAMARGO, 2003, p.54).

Contudo, de acordo com Machado (1997), a medicina é ainda considerada como uma profissão com significativo reconhecimento social, o que contribui para o fato de que raramente seu profissional abandone o ofício. No entanto, há sinais de insatisfação associados a indicadores de adoecimento e sofrimento mental, como evidencia o estudo realizado no Reino Unido por Coombere colaboradores (2002). Para Nogueira Martins (2003), a saúde mental dos médicos, a partir da constatação de uma vulnerabilidade, de causa multifatorial, relacionadaà organização do trabalho, favorece o desenvolvimento de processos patológicos. O autor destaca, ainda, como esses processos podem iniciar, de forma prematura, ainda na fase de formação do profissional.

No que diz respeito mais especificamente aotrabalho em UTI, Fogaça et al. (2008, p.264) afirmam que o ambiente de uma UTI pode atuar de forma negativa sobre a saúde de seus profissionais, porquanto são lugares que geram situações 
de tensão e estresse, motivados pela frequente oscilação entre sucesso e fracasso e pelas exigências impostas à equipe. Os autores chamam atenção para o fato de as UTIs neonatais serem espaços laborais que utilizam tecnologia muito avançada, demandando atualização constante das equipes. Ainda segundo os autores, a sobrecarga de trabalho, caracterizada principalmente por superlotação, falta de preparo da equipe técnica e espaço físico inadequado, influencia a qualidade de vida no trabalho (FOGAÇA et al., 2008).

Neste artigo, temos como objetivo principal conhecer a perspectiva de médicos sobre a saúde e o trabalho em UTI neonatal de um hospital público do Rio de Janeiro.

\section{Pressupostos teóricos}

No que tange à relação entre saúde e trabalho, adotaram-se alguns pressupostos teóricos do campo da saúde do trabalhador e, complementarmente, lançou-se mão dos preceitos da psicodinâmica do trabalho (DEJOURS, 2011) e do conceito vitalista de saúde (CANGUILHEM, 2010).

Toma-secomo significação basilar a ideia de que o campo da Saúde do Trabalhador se constitui como um conjunto de práticas e conhecimentos com o propósito principal de conhecer e transformar as relações entre a saúde e o trabalho. Nele, um dos pressupostos teóricos fundamentais diz respeito à referência capital do reconhecimento da centralidade do trabalho no mundo social (ANTUNES, 2009) e a sua determinação sobre o processo saúde-doença dos grupos humanos (LACAZ, 2007). Compreende-se que as relações sociais são determinadas pelo modo de produção econômico e social, conforme preconiza a corrente de pensamento do materialismo histórico (MARX, 1974). Nessa perspectiva, Harvey (2011) assegura que a geografia histórica do trabalho no capitalismo está marcada por uma incrível flexibilidade com consequências inesperadas para a saúde humana. Convergente com esta concepção, Alves (2013) afirma que uma das principais expressões do capitalismo global é a precarização do trabalho e o adoecimento da subjetividade do trabalho, sob a égide da ordem salarial. Outro importante aspecto citado pelo autor, no que se refere aos traços do processo de precarização, é a assunção segundo a qual no modo de produção capitalista o trabalho perde sentido como fator de realização do homem, já que degradam-se as relações sociais e humanas no processo de produção. 
A rigor, entende-se com Dejours (2011) que o trabalho é central na vida das pessoas como operador de identidade e como importante ativador na realização de si mesmo. De acordo com o autor, "o trabalho é um gerador de saúde ou, ao contrário, um constrangimento patogênico" (DEJOURS, 2011, p.164). O trabalho jamais é neutro e pode levar o sujeito para a descompensação. Nesse enfoque, compreende-se queas situações de trabalho mobilizamprocessos subjetivos e intersubjetivos. Há, em verdade, uma dinâmica entre sofrimento e prazer dos trabalhadores - sofrimento este compatível com a normalidade e que, para manter o equilíbrio psíquico, gera-se uma série de procedimentos de regulação, também chamados de "procedimentos defensivos". O sofrimento e o prazer são situações subjetivas e individuais. Mas quando vários sujeitos experimentam um sofrimento único, estes são capazes de unir seus esforços para construir uma estratégia defensiva coletiva, permitindo ao trabalhador uma estabilidade a qual ele seria incapaz de garantir apenas com defesas individuais (DEJOURS; ABDOUCHELI; JAYET, 1994, p.124).

Outro importante pressuposto teórico existente no campo da saúde do trabalhador é aquele segundo o qual o trabalhador é visto como sujeito do conhecimento a respeito do seu próprio trabalho. Nessa vertente, os trabalhadores deixam de ocupar a posição de objeto de estudo para ocuparem a posição de sujeitos do conhecimento a respeito das mudanças necessárias nos ambientes laborais de modo a se promover saúde (GOMEZ, 2011).

Quanto à concepção de saúde, buscou-se inspiração no conceito vitalista de saúde (CANGUILHEM, 2010), no quala ideia de homem "saudável" firmase em relação à capacidade de se transformar e recriar novas normas de vida frente às adversidades do meio. Esse pensamento contribuiu de forma decisiva para compreendermos como os trabalhadores desenvolvem experiências e produzem conhecimentos ao transformarem tarefas prescritas em trabalho real (CANGUILHEM, 2010; BRITO, 2011).

\section{Metodologia}

Trata-se de uma pesquisa qualitativa, de caráter exploratório a respeito da relação entre a saúde e o trabalho dos médicos da UTI neonatal. Na abordagem qualitativa, segundo Minayo (2007), cabe ao pesquisador usar um acurado instrumental teórico e metodológico que o municie de modo a se aproximar 
e compreender a realidade, ao mesmo tempo em que deve manter a vigilância

crítica permanente sobre o objeto e o processo de produção de conhecimento. Nesse enfoque, o conhecimento é percebido como um desafio, já que a vida e as relações sociais têm a qualidade da multiplicidade e da complexidade.

O presente estudo foi realizado na UTI Neonatal de um hospital público no município de Volta Redonda-RJ, sendo que a escolha do hospital se deu em função do critério de acessibilidade. De um total de 334 médicos lotados no hospital, 23 estavam no setor da UTI neonatal. Ressalte-se que somente um médico é concursado e todos os demais são prestadores de serviço - portanto, sem vínculo trabalhista estável. Do universo de 23 profissionais, três encontravam-se de licença médica, três eram residentes de pediatria, três se recusaram participar e um estava fazendo estágio fora do país. Desta forma, foram realizadas 13 entrevistas.

Observe-se que o grupo de médicos da referida UTI neonatal é formado, na maioria, por mulheres (apenas um profissional é do sexo masculino e não concordou em participar do estudo), com idade maior que 29 anos. O estado civil predominante era o casado, e o tempo de profissão variou de três a 20 anos. Tais resultados são semelhantes às pesquisas realizadas pelo Conselho Federal de Medicina (CFM) em 2004 (CARNEIRO; GOUVEIA, 2004) e 2007 (BARBOSA et al., 2007), nas quais se verificou que a pediatria é uma especialidade composta predominantemente por profissionais do sexo feminino. Destarte, ao nos referirmos aos sujeitos deste estudo, usaremos a flexão dos termos no gênero feminino.

Foram realizadas entrevistas semiestruturadas e individuais. Para preservar a identidade das entrevistadas, adotamos um artifício de identificação e apresentação das falas: usamos a letra E (entrevistada) para todos os participantes, seguida da ordem cronológica de realização das entrevistas. Assim, por exemplo, E1 representa a primeira entrevistada e E13, a última.

Adotamos como procedimento de análise dos dados a "análise do discurso" (GILL, 2008; MINAYO, 2007), tendo como matéria de interpretação o discurso dos médicos de UTI neonatal. Para essa perspectiva, o discurso tem importância central na construção da vida social, "é construído ou manufaturado pelos diversos atores sociais" (GILL, 2008, p.247). A análise do discurso pode ser caracterizada como uma teoria crítica que trata da determinação histórica dos processos de significação. Tem como foco central de análise a relação entre linguagem e seu 
contexto de produção, e procura problematizar as evidências revelando que não há discurso sem sujeito, nem sujeito sem ideologia.

Seguindo a linha de formulação das autoras (GILL, 2008; MINAYO, 2007), constituiu-se o corpus de pesquisa tomando como objeto de análise o texto das entrevistas com os trabalhadores, do qual, após sucessivas leituras, foram extraídos os "núcleos de compreensão do texto" ou categorias empíricas de análise. Deste modo, realizamos duas operações classificatórias dos materiais advindos das entrevistas: a primeira, onde destacamos tais núcleos, agrupando os trechos das entrevistas por homogeneidade e significações de semelhança. Quanto ao segundo procedimento classificatório, organizamos tais núcleos sob títulos que são nossos temas de análise, os quais foram denominados de "eixos de análise", sendo eles: elementos da atual configuração do trabalho médico; o trabalho na UTI neonatal; a saúde dos médicos e a prática de automedicação; gênero no trabalho médico e na pediatria. Em síntese, organizamos a apresentação de nossos resultados por eixos de análise, interpretando esses materiais em diálogo com a literatura atual.

Esta pesquisa foi aprovada pelo Comitê de Ética em Pesquisa da ENSP/ FIOCRUZ (CEP/ENSP), registrado sob o CAAE03449012.7.0000.5240.

\section{Resultados e discussão}

\section{Eixo I- Elementos da atual configuração do trabalho médico}

É não colocar nas suas costas uma missão divina, porque você é humano. Essa história de sacerdócio atrapalha muito o próprio médico. A gente costuma ter uma exigência com a gente que não é normal e que não é justa (E2).

É uma coisa que faz você ir pra frente, assim é meio que uma parte da sua alma (E10).

Nas entrevistas, identificou-se uma percepção crítica, presente no discurso das médicas entrevistadas, em relação a certa exigência da sociedade de um suposto dom sagrado por parte daqueles que escolhem exercer a medicina. Por outro lado, identificaram-se falas que assumem exatamente essa posição criticada, qual seja, que a prática da medicina envolve sentimentos elevados. De acordo com Espert e Rivero (2004), a decisão de estudar medicina está relacionada à existência de sentimentos humanitários como característica de personalidade. Do mesmo modo, para Dichi e Dichi (2006), a maioria dos estudantes de medicina 
procura, de fato, a profissão médica por questões humanitárias, embora alguns

o façam por motivos menos altruísticos, como status e recompensa financeira. Identificamos na fala dos entrevistados a expressão de sentimentos conflitantes que se colocam entre a "missão sagrada" e o desgaste do trabalho concreto. Com efeito, existe um distanciamento entre os valores sociais relacionados à escolha pela profissão e a prática médica concreta em saúde.

Lima et al. (2004) chamam atenção para o fato de que as exigências do trabalho do médico podem evidenciar uma quebra dos valores da dignidade, do espírito e da vontade. Para os autores, o desgaste físico e emocional a que estão esses trabalhadores submetidos pode gerar um processo gradual de perda de energia, pois, cada vez mais, o ambiente profissional prioriza valores econômicos em detrimento dos humanos. Atualmente, observa-se o aumento na sobrecarga de horas de trabalho e remuneração incompatível com o trabalho. Constataramse, nas entrevistas, o multiemprego e o aumento do número de horas trabalhadas, principalmente sob a forma de plantões ou mesmo do acúmulo de funçôes.

Hoje em dia, pra valer a pena você trabalhar como médico, você tem que trabalhar muito. Então, o que acontece no consultório, por exemplo, é que você tem que atender um atrás do outro (E12).

As transformações ocorridas na organização do trabalho médico evidenciam um cenário bastante desfavorável a esses trabalhadores: sobrecarga de trabalho, especialmente em atividades de plantão; condições de trabalho precárias, regidas preferencialmente pela remuneração por procedimento, sobretudo no setor privado; baixa remuneração e elevada frequência de queixas físicas e psíquicas. As condições de trabalho e saúde observadas apontam para a necessidade de mudanças profundas na organização do trabalho médico (TEIXEIRA et al., 2008).

Quanto à observação "pra valer a pena você trabalhar como médico, você tem que trabalhar muito", salta aos olhos o aspecto referente à baixa remuneração médica. Essas percepções assemelham-se aos resultados obtidos em outro estudo (SOBRINHO et al., 2006), no qual os autores fazem referência à atual situação, generalizada, de precarização do trabalho médico por meio da constatação do crescimento da informalidade desta atividade profissional, do aumento do trabalho por procedimento, da ampliação da subcontratação e da expansão da terceirização no setor público e, por fim, da redução do trabalho médico na condição de assalariado. Contudo, o que ocorre com maior frequência é a 
combinação dessas formas de inserção dos médicos no mercado de trabalho (NASCIMENTO SOBRINHO; NASCIMENTO; CARVALHO, 2005).

Eu de folga tenho o sábado. Vinte e quatro horas que eu tenho de folga por semana, trabalho 144 horas (E11).

Eu não trabalho domingo. Eu pus isso como objetivo: domingo eu não trabalho, é sagrado (E4).

Nas entrevistas, ficou claro o excessivo número de horas trabalhadas pelas médicas entrevistadas. Em estudo realizado pelo CFM (BARBOSA et al., 2007), constatou-se que a maioria dos entrevistados exercia até três atividades de modo simultâneo, e cerca de um quinto dos médicos dedicava de 61 a 100 horas por semana ao trabalho. Essa jornada está excessivamente acima do estabelecido pela legislação trabalhista (CLT), de 44 horas semanais.

Percebe-se uma naturalização da ausência de pausas na rotina laboral médica. Trabalhar sem descansos parece ser considerado algo trivial, um hábito profissional, que foi mencionado pela maioria dos entrevistados, sem muita ponderação crítica. Assim sendo, o trabalho ininterrupto é entendido como aquilo que se tornou parte da rotina do médico, e quando se referem às folgas, o fazem como algo sagrado e atípico.

$\mathrm{Na}$ perspectiva ergonômica, a insuficiência de pausa repercute negativamente sobre a saúde e a vida social dos trabalhadores, visto que a pausa não é somente um tempo destinada à recuperação, já que o organismo humano obedece a ritmos biológicos; ela tem igualmente um caráter social que favorece a trocas úteis e a emergência do campo criativo de trabalho (GUÉRIN et al., 2012).

Eu dependo muito do meu trabalho. Acho que agora já é um vício. Final de semana que não tem nada, o que é uma coisa rara, eu fico "nossa, o que eu faço?” (E9).

Sou um pouco workholic, se eu não estou trabalhando, não sei bem o que eu faço (E3).

Sobre a dedicação à profissão, observamos o depoimento de profissionais que não se reconhecem fora do ambiente de trabalho, como constatou o estudo de Machado (1997). Para a autora, poucas são as profissões, como a medicina, em que o mundo do trabalho se funde, e por vezes se confunde, com o mundo da vida. Segundo Lancman e Sznelwar (2011), o excesso de dedicação ao trabalho pode ser visto como uma resposta subjetiva do trabalhador, incitada pela organização do trabalho. 
A gente tem sempre que examinar os pacientes, discutir, definir de acordo com o exame da criança no dia, definir a medicação e observar a criança praticamente o tempo inteiro (E8).

O clima de tensão é uma coisa que incomoda. Tem criança grave (E4).

$\mathrm{O}$ ponto que se coloca em destaque diante dos relatos que descrevem o acúmulo de tarefas e o forte clima de tensão no trabalho da UTI neonatal éo tema da intensificação do trabalho do médico e suas repercussões na saúde. Para a ergonomia (GUÉRIN et al., 2012), a acepção de intensificação está relacionada à mobilização das capacidades cognitivas e fisiológica dos trabalhadores. Entretanto, o sentido de intensificação, quando empregado ao trabalho do médico intensivista, parece sugerir um atributo natural a esse tipo de labor. Trata-se de um trabalho realizado sob forte clima de tensão, que exige do profissional de saúde um estado constante de atenção e vigilância. Para Dal Rosso (2006), a compreensão da noção de intensidade laboral requer focalização sobre a pessoa do trabalhador ou seus coletivos. Sempre que se fala em intensidade do trabalho, deve-se voltar a atenção para a análise de quem trabalha. Do trabalhador é exigido algo a mais, um empenho maior, seja físico, intelectual ou psíquico. Portanto, a atenção carece estar centrada sobre quem trabalha, pois a intensidade do trabalho é mais que esforço físico; envolve todas as capacidades do trabalhador, de seu corpo, da sua afetividade e dos saberes adquiridos através do tempo ou transmitidos pelo processo de relações estabelecidas com outros trabalhadores e sem as quais o trabalho se tornaria inviável. Para o autor, é imprescindível investigar mais a fundo os efeitos que a intensificação do trabalho produz sobre a saúde dos trabalhadores, já que, de acordo com suas pesquisas, existe um padrão de problemas a serem enfrentados no futuro com o trabalho imaterial intensificado. Poderíamos afirmar que, por sua natureza e características, o trabalho em UTI está naturalizado como um trabalho de caráter intensificado. Além disso, os médicos vivem sob a forte tensão da possibilidade de perda do paciente.

É claro que o pior ponto negativo é perder paciente. É você lidar com a perda, de uma forma que não é pontual, ou que não é uma exceção, mas que pode ser uma rotina do seu trabalho. Criança grave morre em UTI. Isso não tem dúvida. Lidar com a perda, pode ser uma rotina do seu trabalho (E2). 

coisas que você não aceita na hora. Às vezes passa pela sua cabeça, será que você precipitou? (E8).

O tema da morte apareceu durante as entrevistas com um forte sentido de padecimento no trabalho e parece ser visto como parte da rotina do médico de UTI. Baasch e Laner (2011) destacam a morte como o momento que mais desgasta a rotina do profissional de saúde no cotidiano de sua atuação. Por não serem imunes às reações emocionais, tais profissionais constroem, como mecanismo de defesa, ao longo dos anos, uma "armadura", por muitos entendida como "frieza", a fim de omitir a existência, um misto de sentimentos de impotência, culpa, fracasso, medo e, principalmente, a dificuldade e o despreparo para lidar com a situação, com as pessoas e os sentimentos envolvidos. De acordo com os autores, esses sentimentos se exacerbam quando o óbito ocorre durante a infância, visto que esta representa um ciclo de vida que não se cumpre, por ser mais desprotegida e por ser "símbolo da nossa imortalidade". Na sociedade ocidental, a morte é representada pelo pavor e pela necessidade imperativa e quase ritualizada de negação. $\mathrm{O}$ processo de socialização não concebe a morte e não prepara os indivíduos para sua vivência. Destarte, o despreparo sentido pelos médicos e por outros profissionais da saúde na abordagem da questão da morte antecede a própria formação profissional.

Koifman (2001) ressalta a hegemonia do modelo biomédico na formação médica em detrimento de outras ciências como importante fator sobre este despreparo. Consoante a autora, há uma idealização da prática médica. Tudo se passa como se o médico aprendesse a discorrer sobre as doenças para esquecer o fato definitivo da morte. Esse esquecimento, porém, afasta a medicina de um aspecto essencial da natureza humana: a consciência da fragilidade e a certeza da morte. A inclusão do social, do psicológico e do tema da morte, pode contribuir para uma visão diferenciada e mais abrangente de saúde, do que aquela voltada somente para as questões orgânicas. Contudo, os entrevistados mencionaram aspectos positivos do ambiente de trabalho.

O ambiente da "neo", apesar de ser um ambiente estressante, é um ambiente que tem uma humanização. É um setor que é o mais humanizado dentro da medicina (E13).

O tema da humanização apareceu de modo recorrente durante as entrevistas, com um enfoque afirmativo sobre o trabalho. Souza e Ferreira (2010) afirmam 
que os desafios para uma abordagem humanizada no âmbito da UTI neonatal são grandes. Para Hennington (2008), a consolidação de uma política de humanização exige mudanças no modelo de gestão e de atenção à saúde. A autora considera que humanizar é ofertar atendimento de qualidade, articulando os avanços tecnológicos com acolhimento, com melhoria dos ambientes de cuidado e das condições de trabalho dos profissionais. Portanto, nessa linha de compreensão, deve-se pensar a produção de cuidados e práticas humanizadoras levando em conta as especificidades do labor do médico que envolve a utilização "intensiva" de capacidades físicas e psíquicas, intelectual e emocional. Isso sem contar a convivência diária com toda forma de sofrimento, que parece ser inseparável do universo da saúde e da doença, da vida e da morte, e com inevitáveis repercussōes no corpo e na alma dos trabalhadores (HENNINGTON, 2008). Em que pesem os problemas da rotina de trabalho de uma UTI neonatal, no decurso das entrevistas foram ressaltados aspectos relacionados à satisfação e ao prazer no trabalho.

É a satisfação do que eu faço. Eu gosto de fazer UTI, eu gosto. É uma coisa que você vê um resultado, quando você tem tudo na mão pra fazer pela criança, é uma coisa muito dinâmica e eu gostei muito disso (E3).

Em todas as entrevistas, ouvimos das participantes a afirmação de que gostam de trabalhar em UTI neonatais. Sobressai nessas declarações a ideia da possibilidade de maior controle sobre as intercorrências no quadro das crianças internadas por meio de aparelhos tecnológicos. Ao definir os neonatologistas, Mathelin (1999) refere que são os pediatras que foram trazidos pela paixão pela medicina de alta tecnologia. Em concordância, Nogueira (2012) afirma que essa tecnologia pode ser vista como a extensão dos sentidos humanos e de suas funções motoras e sensoriais, expressando, portanto, o desejo da medicina ocidental de dominar e controlar o corpo, seus processos naturais e suas doenças. Por sua vez, a assimilação de um padrão de medicina de alto tecnicismo induz a clientela a exigir do médico a inclusão de recursos sofisticados, tornando-o um operador da máquina ou mesmo um instrumento da máquina, sendo o paciente visto como um objeto que viabiliza o funcionamento da máquina e a relação entre eles acontecendo em função do equipamento.

É interessante observar que, a despeito da polêmica relação entre o uso de medicina de alta tecnologia e o declínio das relações humanizadas entre médicos e pacientes, os participantes das entrevistas destacam como positivo o acesso 
a aparelhos tecnológicos no que se refere ao trabalho do médico em UTIs. Percebe-se que a consciência da existência de mecanismos de controle para atuar em possíveis intercorrências, no quadro de saúde dos pacientes internados, tem efeito positivo na economia psíquica desses trabalhadores. Por conseguinte, a carência de recursos no cotidiano laboral do médico é uma fonte de sofrimento desta categoria profissional, sobretudo se levarmos em consideração o desgaste emocional do médico em relação à possibilidade da ocorrência de "erro médico" (MINOSSI, 2009).

[...] às vezes você trabalha sozinho, trabalha no limite, você sabe que não pode dar atenção que você deveria dar a todas as crianças, que você é um só. Isso é uma coisa que me incomoda um pouco. No outro serviço a gente trabalha em dupla e eu acho que funciona melhor [...] (E3).

[...] eu acho que o principal é o relacionamento médico enfermagem, mas eu acho que o principal é isso. Se não for bom, tudo flui com dificuldade, eu acho (E11).

Embora o número de profissionais de UTI seja definido por normas técnicas bem estabelecidas (AMIB, 2009; SBP 2010; BRASIL, 2005) em relação à capacidade de funcionamento, os entrevistados pontuam a importância da presença de mais neonatologistas no plantão não só para partilhar o serviço, mas também para compartilhar condutas de emergência, visto que o médico da rotina cumpre carga horária diferente.

Quanto ao tema de relacionamento com a equipe, temos a considerar, a partir dos depoimentos, que a não integração dos médicos com seu grupo de trabalho pode representar um fator potencializador de tensão nas relações laborais. Fogaça et al. (2010) concluem que médicos de UTI neonatal apresentam variáveis níveis de tensão psicológica - tensão que está diretamente relacionada ao grau de interação social e emocional e da confiança que se estabelece entre os membros da equipe.

O trabalho em cooperação, entre membros de uma mesma categoria profissional (médico-médico) ou entre categorias diferentes (médico-enfermeira; médico-técnicos de enfermagem, entre outras), representa a vontade das pessoas de superarem coletivamente as contradiçôes que surgem da própria natureza ou da essência da organização do trabalho, sendo decisivo tanto em relação à eficiência do trabalho quanto à economia do sofrimento e favorecimento do prazer no trabalho (GUÉRIN et al., 2012; LANCMAN e SZNELWAR, 2011).

A conclusões semelhantes chegaram Silva, Silva e Christoffer (2009), quando afirmam que a importância do relacionamento interpessoal nos espaços 
do cuidado em saúde implica o resgate da subjetividade, mantendo nesses profissionais o encantamento e o prazer pelo trabalho realizado e a satisfação da família pelo cuidado e acolhimento recebido.

\title{
Eixo III- A saúde dos médicos: a prática de automedicação e a necessidade de espaços de diálogo
}

\begin{abstract}
Muita automedicação, porque médico sempre se automedica. Não adianta dizer que não. Então a gente acha que sentiu dor, basta tomar um remédio e acabou a dor, como se tivesse acabado o problema e acha que é normal. É normal porque quem dá plantão e está em um monte de lugar vai dormir mal, vai viver mais cansado, vai ter mais dor de cabeça, vai ter mais dor nas costas, então é normal do trabalho (E8).
\end{abstract}

Identificou-se, nas entrevistas, o ponto referente à automedicação.Apesar de não se considerarem doentes, as participantes referiram queixas de insônia, distúrbios do sono, asma, cefaleia, dores musculares, alteraçōes do humor, taquicardia, estresse, depressão, hipertensão arterial, gastrite, queda de cabelo e tensão. Para Barbosa et al. (2007), o desgaste resultante de jornadas de trabalho exaustivas frequentemente leva os médicos a negligenciarem a preservação de sua saúde, predispondo-os ao adoecimento em proporções até mesmo superiores às das pessoas a quem prestam assistência, visto que suas atitudes frente aos sinais e sintomas de enfermidades costumam ser principalmente de autodiagnóstico e automedicação e/ou consulta informal com algum amigo médico. Nogueira Martins (2003), Pinto; Almeida; Miyazaki (2010) e Luz et al. (2012) consideram essas atitudes como características da "desadaptação" dos profissionais frente aos fatores estressantes inerentes à prática médica. Observemos que a ideia de "desadaptação", como falta de adaptação, sugere a necessidade de prover, no caso do trabalho dos médicos de UTI, a adaptação do trabalho ao trabalhador, como bem preconiza a ergonomia da atividade (GUÉRIN et al., 2012), rompendo com a concepção, oriunda da saúde ocupacional, de que o controle aos danos à saúde dos trabalhadores se efetivará caso o trabalhador se ajuste ao trabalho.

Sinto falta aqui, por exemplo, é de um espaço, de uma sala para a gente discutir as coisas, algo mais específico (E10).

Porque o médico está acostumado a só ouvir tudo de todos, mas ninguém para para ouvir a gente. A gente pode estar com problema e finge que não está porque a gente só fica absorvendo, ouvindo, ouvindo, ouvindo. Então, a gente precisava de alguém para ouvir a gente também (E12). 
Com base na fala dos entrevistados, constatou-se a necessidade de criar um espaço, no próprio trabalho, para que os médicos falem sobre problemas relacionados à saúde e ao cotidiano laboral. As queixas dos entrevistados expressam a necessidade de serem ouvidos e sugerem a importância da adoção de medidas que auxiliem os profissionais a lidar com os aspectos subjetivos da prática assistencial, levando em conta os fatores estressantes da atividade e o favorecimento das relações de trabalho em equipe. Desta forma, o cuidado com a saúde do profissional de saúde é fundamental para o aprimoramento da atividade assistencial, conforme colocado por Nogueira-Martins (2003).

Segundo Rios (2007), vários estudos com profissionais da área da saúde demonstram ser esta uma população particularmente susceptível ao sofrimento psíquico e ao estresse, devido ao trabalho, o que aponta a necessidade de criar dispositivos institucionais para seu cuidado. De acordo com a autora, tais dispositivos começam pela criação de espaços de fala e escuta, provocando descobertas por meio do diálogo. São espaços que devem tratar das inquietaçôes decorrentes do trabalho cotidiano por meio de atividades com grupos de caráter pedagógico, sob a orientação de profissional qualificado para oferecer suporte social às vivências laborais (SOUZA; FALLEIROS, 2011).

\section{Eixo IV- Gênero no trabalho da UTI e a pediatria}

[...] a UTI neonatal é o útero e a gente é a mãe daquele bebê. Por isso que a gente aguenta. Porque a mulher aguenta muita coisa. Mulher consegue dar conta de trabalhar, dobrar plantão, dá conta de filho, marido, casa... eu acho que é uma especialidade que é da mulher (E13).

Sempre brinquei de boneca. Então quando entrei para a medicina eu sabia que queria ser pediatra (E12).

Outro ponto que se destacou, a partir da análise das falas das entrevistadas, diz respeito às questóes de gênero no trabalho médico. Observou-se credulidade, por parte das entrevistadas, sobre a relação entre as qualidades naturais do gênero feminino e os atributos do trabalho como pediatra da UTI neonatal. São dignas de nota as duas comparações da entrevistada E13 a respeito do espaço da UTI e o útero materno e, ainda, entre a função de médica e o papel de mãe. Segundo Chies (2010), a pediatra é a "dona de casa da medicina”, assim o mito do instinto maternal tornaria a mulher mais calma, propícia à arte do "cuidar"; logo, apta 
a trabalhar com o tratamento de enfermos de doenças crônicas e pacientes que necessitam de cuidado contínuo e próximo. Para a autora, os homens, reconhecidos pela postura agressiva e sem titubeios, seriam adequados, por exemplo, à precisão necessária em manobras cirúrgicas.

Araújo e Rotenberg (2011) consideram que, nas sociedades contemporâneas, o trabalho dos homens e das mulheres ainda mantém características muito diferenciadas, com atribuiçôes de valor e de reconhecimento estruturadas com base nas diferenças de sexo, mesmo quando se analisa uma mesma ocupação. No hospital, por exemplo, observa-se o predomínio dos homens nas ações de tratamento desempenhadas pelos médicos, ao passo que as mulheres permanecem responsáveis pelas atividades de cuidado. Assim, estabelece-se uma divisão sexual do trabalho ancorada em concepções que estabelecem, por um lado, as funções masculinas baseadas em competências adquiridas no processo de qualificação e, por outro, as funções femininas, cujas exigências permanecem ligadas às qualidades do sexo.

\section{Considerações finais}

Neste estudo, destacamos a ideia de acordo com a qual as transformações técnicas e organizacionais do trabalho médico vêm se acelerando e gerando significativas consequências para a vida e a saúde desses trabalhadores. Nas entrevistas, são mencionadas pelas médicas participantes do estudo a situação generalizada da ausência de vínculos trabalhistas estáveis e a precedência de escolha pela atividade de plantões, visto como trabalho assalariado com maior retorno financeiro, embora com carga maior de trabalho.

Foi possível constatar, nos depoimentos, queixas relativas ao ambiente e ao trabalho da UTI neonatal, tais como:confinamento, tensão, cobrança por resultados, possibilidade constante da "perda" do paciente e falta de suporte psicológico que podem repercutir na saúde e subjetividade desses trabalhadores. Além disso, verificou-se que o relacionamento entre os participantes de uma equipe e destes com os usuários é fator decisivo para o êxito do trabalho e para transformação do sofrimento em prazer e satisfação laboral. Verificou-se o ponto referente à negligência dos médicos em relação a sua própria saúde, predispondo-os ao autodiagnóstico e à automedicação em níveis variados. Observou-se que, apesar da carga horária elevada, as entrevistadas buscam, sempre que possível, manter atividades de lazer e convívio familiar, atuando de forma favorável sobre a saúde. 
Pode-se concluir que a falta de condições adequadas de trabalho e os equívocos na organização laboral colocam em risco a saúde dessas trabalhadoras, sobretudo quando as estratégias de defesa utilizadas parecem não estar sendo suficientes (DEJOURS; ABDOUCHELI; JAYET, 1994). Existe o reconhecimento de que o trabalho em UTI é marcado por emoções, conflitos e sentimentos, requerendo da equipe permanente vigilância à saúde dos trabalhadores da saúde. Destacou-se, no entanto, a ideia de satisfação no trabalho em UTI na maioria das entrevistas.

Um fator observado e de grande relevância é a questão de gênero e o trabalho médico, necessitando de novos estudos para aprofundar aspectos relativos à precarização do trabalho e a saúde sob a perspectiva da organização sexual do trabalho.

Constatamos que as condições de trabalho e saúde observadas neste estudo apontam a necessidade de mudanças na organização do trabalho médico em UTIsneonatais, com políticas de valorizaçãoprofissional abrangente e ações a partir dos locais de trabalho.

Por fim, a proposta de grupos de diálogo, no próprio espaço laboral, pode proporcionar a criação de ambientes favoráveis ao compartilhamento de problemas e soluções relacionados ao trabalho, por meio da fala e da escuta, possibilitando uma dinâmica na qual o trabalhador venha a ser sujeito de mudanças, como nas palavras dos trabalhadores, da "situação limite" em que se encontram o trabalho e a saúde dos médicos de UTIs neonatais. ${ }^{1}$

\section{Referências}

ALVES, G. Dimensōes da precarização do trabalho: ensaios de sociologia do trabalho. Bauru: Canal 6, 2013.259p.

ANTUNES, R. Os sentidos do trabalho: ensaio sobre a afirmação e a negação do trabalho. São Paulo: Boitempo, 2009. 287p.

ARAÚJO T. M.; ROTENBERG, L. Relações de gênero no trabalho em saúde: a divisão sexual do trabalho e a saúde dos trabalhadores. In: ASSUNÇÃO, A. A.; BRITO, J. (Org.). Trabalhar na saúde: experiências cotidianas e desafios para a gestão do trabalho e do emprego. Rio de Janeiro: Fiocruz, 2011, p. 130-150.

ASSOCIAÇÃO DE MEDICINA INTENSIVA BRASILEIRA. Regulamento técnico para funcionamento de unidades de terapia intensiva. São Paulo: AMIB, 2009. Disponível em: <http://www.amib.org.br/fileadmin/RecomendacoesAMIB.pdf>. Acesso em: 29 dez. 2012. 
BAASCH, D.; LANER, A. S. Os significados do trabalho em unidades de terapia intensiva de dois hospitais brasileiros. Ciência e Saúde Coletiva. Rio de Janeiro, v. 16, supl. 1, p. 1097$1105,2011$.

BARBOSA, G. A. et al. (Org.). A saúde dos médicos no Brasil. Brasília: Conselho Federal de Medicina, 2007. 220p.

BRASIL. Ministério da Saúde. Secretaria de Políticas Públicas de Saúde. Agenda de Compromissos para a Saúde Integral da Criança e a Redução da Mortalidade Infantil. Série A. Normas e Manuais Técnicos. Brasília: Ministério da Saúde, 2005.

BRITO, J. A ergologia como perspectiva de análise: a saúde do trabalhador e o trabalho em saúde. In: GOMEZ, C. M.; MACHADO, J. M. H; PENA, P. G. L (Orgs). Saúde do trabalhador na sociedade brasileira contemporânea. Rio de Janeiro: Fiocruz, 2011, p. 479-494.

CAMARGO, K. R. Biomedicina, saber e ciência: uma abordagem crítica. São Paulo: Hucitec, 2003. 195p.

CANGUILHEM, G. O normal e o patológico. Rio de Janeiro: Forense Universitária, 2010. 277p.

CARNEIRO, M. B.; GOUVEIA, V. V. (Org.). O médico e o seu trabalho. Brasília: Conselho Federal de Medicina, 2004.

CHIES, P. V. Identidade de gênero e identidade profissional no campo de trabalho.Rev. Estud. Fem. Florianópolis, v. 18, n. 2, p. 507-528, 2010.

COOMBER, S. et al. Stress in UK intensive care unit doctors. British Journal of Anesthesia. London, v. 89 n. 6, p. 873-881, 2002.

DAL ROSSO, S. Intensidade e imaterialidade do trabalho e saúde.Trab. Educ. Saúde. Rio de Janeiro, v. 4, n. 1, p. 65-92, 2006.

DEJOURS, C. O trabalho como enigma. In: LANCMAN S.; SZNELWAR L, (Org.). Christophe Dejours: da psicopatologia à psicodinâmica do trabalho. Rio de Janeiro: Fiocruz, 2011. p. 127-140.

DEJOURS, C.; ABDOUCHELI, E.; JAYET, C. Psicodinâmica do trabalho: contribuições da Escola Dejouriana à análise da relação prazer, sofrimento e trabalho. São Paulo: Atlas, 1994. DICHI, J. B.; DICHI, I. Agonia da história clínica e suas consequências para o ensino médico.Rev. bras. educ. med. Rio de Janeiro, v. 30, n. 2, p. 93-97, 2006.

ESPERT, A. F.; RIVERO, C. F. El humanismo del Che. RevHum Med. Cuba, v. 4, n. 2, 2004. FOGAÇA, M. C. et al. Fatores que tornam estressante o trabalho de médicos e enfermeiros em terapia intensiva pediátrica e neonatal: estudo de revisão bibliográfica. Revista Brasileira de Terapia Intensiva. São Paulo, v. 20, n. 3, p. 261-266, 2008.

.Estudo preliminar sobre o estresse ocupacional de médicos e enfermeiros em UTI pediátrica e neonatal: o equilíbrio entre esforço e recompensa. Rev. Latino-Americana de Enfermagem, Ribeirão Preto, v. 18, n.1, 6 telas, p.67-72, 2010. 
GILL, R. Análise do discurso. In: BAUER, M.; GaSkell, G. (Org.). Pesquisa qualitativa com texto, imagem e som. Petrópolis: Vozes, 2008. p. 244- 270.

GOMEZ, C. M.; MACHADO, J. M. H; PENA, P. G. L. Saúde do trabalhador na sociedade brasileira contemporânea. Rio de Janeiro: Fiocruz, 2011, 539p.

GOMEZ, C.M. Campo da saúde do trabalhador: trajetória, configuração e transformações. In: GOMEZ, C. M.; MACHADO, J. M. H.; PENA, P. G. L. (Org.). Saúde do trabalhador na sociedade brasileira contemporânea. Rio de Janeiro: Fiocruz, 2011. p. 23-36.

GUÉRIN, F. et al. Compreender o trabalho para transformá-lo: a prática da ergonomia. São Paulo: Edgard Blücher/Fundação Vanzolini, 2012. 200p.

HARVEY, D. O enigma do capital: e as crises do capitalismo. São Paulo: Boitempo, 2011. 235p.

HENNINGTON, E. A.Gestão dos processos de trabalho e humanização em saúde: reflexōes a partir da ergologia.Rev. Saúde Pública. São Paulo, v. 42, n. 3, p. 555-561, 2008.

Entre o criativo e o precário: reflexões sobre constrangimentos e possibilidades do trabalhador de saúde em tempos líquidos. In: MINAYO, C. G.; MACHADO, J. M. H.; PENA, P. G. L. (Org.). Saúde do trabalhador na sociedade contemporânea brasileira. Rio de Janeiro: Fiocruz, 2011. p.433-452.

KOIFMAN, L. O modelo biomédico e a reformulação do currículo médico da Universidade Federal Fluminense. História, Ciências, Saúde. Rio de Janeiro, v. VIII, n. 1, p. 48-70, 2001.

LACAZ, F. A. C. O campo saúde do trabalhador resgatando conhecimento e práticas sobre as relações trabalho-saúde. Cadernos de Saúde Pública. Rio de Janeiro, v. 23, n. 4, p. 757766, 2007.

LANCMAN, S.; SZNELWAR, L. (Org.). Christophe Dejours: da psicopatologia à psicodinâmica do trabalho. Rio de Janeiro: Fiocruz, 2011. 512p.

LIMA, A. P. B. et al. Síndrome de Burnout em residentes da Universidade Federal de Uberlândia. Rev. Bras. Educ. Med. Rio de Janeiro, v. 31, n. 2, p. 137-146, 2004.

LUZ, T. C. B. et al. Consumo de medicamentos por trabalhadores de hospital. Revista Ciência e Saúde Coletiva. Rio de Janeiro, v. 17, n. 2, p. 499-509, 2012.

MACHADO, M. H. Perfil dos médicos no Brasil. Rio de Janeiro: Fiocruz, 1997. 240p.

MARX, K. Manuscritos econômico-filosóficos. São Paulo: Abril Cultural, 1974.

MATHELIN, C. O sorriso da Gioconda: clínica psicanalítica com os bebês prematuros. Rio de Janeiro: Companhia de Freud, 1999.

MINAYO, M. C. S. O desafio do conhecimento: pesquisa qualitativa em saúde. São Paulo: Hucitec, Abrasco, 2007.

MINOSSI, J. G.Prevenção de conflitos médico-legais no exercício da medicina. Rev. Col. Bras. Cir. Rio de Janeiro, v. 6, n. 1, p. 90-95. 2009. 
NASCIMENTO SOBRINHO, C. L.; NASCIMENTO, M. A.; CARVALHO, F. M.

Transformações no trabalho médico. Revista Brasileira de Educação Médica. Rio de Janeiro, v. 28, n. 2, p. 129-135, 2005.

NOGUEIRA, M. I. Trabalho em saúde e trabalho médico: especificidades e convergências. Rev. bras. educ. med. Rio de Janeiro, v. 36, n. 3, p. 414-422, 2012.

NOGUEIRA-MARTINS, L. A. Saúde mental dos profissionais de saúde. Revista Brasileira de Medicina do Trabalho. Belo Horizonte, v. 1, n. 1, p. 56-68, 2003.

PINTO, D. R.; ALMEIDA, T. E. P.; MIYAZAKI, M. C. O. S. A saúde e estresse ocupacional em médicos. Arquivos de Ciências da Saúde. Curitiba, v. 17, n. 4, p. 201-205, 2010.

RIOS, I. C. Rodas de conversa sobre o trabalho na rua: discutindo saúde mental.Physis: Revistade Saúde Coletiva. Rio de Janeiro, v. 17, n. 2, p. 251-263, 2007.

SILVA, L. J.; SILVA, L. R.; CHRISTOFFEL, M. M. Tecnologia e humanização na Unidade de Terapia Intensiva Neonatal: reflexões no contexto do processo saúde-doença. Rev. Esc. Enferm. USP. São Paulo, v. 43, n. 3, p. 684-689, 2009.

SOBRINHO, C. L. N. et al. Condiçôes de trabalho e saúde dos médicos em Salvador, Brasil.Rev. Assoc. Med. Bras. São Paulo, v. 52, n. 2, p. 97-102, 2006.

SOCIEDADE BRASILEIRA DE PEDIATRIA. Infraestrutura para atendimento integral ao recém-nascido. Documento científico. Departamento de Neonatologia da Sociedade Brasileira de Pediatria. Rio de Janeiro, 21 nov. 2010. Disponível em:<www.sbp.com.br/pdfs/ SBP-DC-Neo-Infraestrutura-integral-21 nov2010aprovado.pdf>. Acesso em: 03 set. 2012.

SOUZA, K. M. O.; FERREIRA, S. D. Assistência humanizada em UTI neonatal: os sentidos e as limitações identificadas pelos profissionais de saúde. Ciência \& Saúde Coletiva. Rio de Janeiro, v. 15, n. 2, p.471-480, 2010.

SOUZA, K. R.; FALLEIROS, I. Para uma práxis educativa em saúde do trabalhador. In: VASCONCELLOS, L.; OLIVEIRA, M. H. (Org.). Saúde, trabalho e direito: uma trajetória crítica e a crítica de uma trajetória. Rio de Janeiro: Educam, 2011. p. 559-598.

TEIXEIRA, G. S. P. et al. Perfil da saúde dos médicos e do exercício profissional na cidade de Barbacena. Revista Médica de Minas Gerais. Belo Horizonte, v. 18, n. 2, p. 100-107, 2008.

\section{Nota}

${ }^{1}$ A. P. F. Rocha participou da concepção do estudo, realizou a pesquisa de campo, a análise dos dados e a redação do artigo. K. R. de Souza participou da orientação do estudo, contribuiu com a análise dos dados e redação final do artigo. L. R. Teixeira participou da orientação do estudo e contribuiu com a redação e aprovação final do manuscrito. 


\section{Health and medical work of neonatal ICU physicians: a study in a public hospital in Rio de Janeiro}

This article aims to know the perspective on health and the work of doctors in a neonatal intensive care in a public hospital in the state of Rio de Janeiro. To this end we carried out a qualitative and exploratory study. Thirteen individual and semistructured interviews with script questions were conducted. Regarding the analysis of the materials, we adopted the discourse analysis technique, and identified four empirical lines of discussion, namely: the current medical work setting elements; work in the NICU; doctors' health and the practice of self-medication and the need for dialogue; gender in medical practice and pediatrics. It was found that the technical and organizational transformations of medical work are accelerating and generating significant consequences for the lives and health of these workers. We also found preponderance of the absence of stable employment relationships and precedence of choice for shifts of activity due to the current salary conditions, generating increased workload. The results confirmed the need for a comprehensive professional development policy that includes changes in work organization from workplaces, with the participation of employees.

> Key words: health worker; medicine and work; neonatal ICU; doctors' health. 